\title{
Improvement of the system of inorganic waste recycling to man-made soils
}

\author{
Konstantin Chertes ${ }^{1}$, Olga Tupitsyna ${ }^{1}$, Vitaliy Pystin ${ }^{1, *}$, Aleksey Savelyev ${ }^{1}$, and Elena \\ Martynenko ${ }^{1}$ \\ ${ }^{1}$ Samara State Technical University (SamSTU), Russia, 443100, 244 Molodogvardeyskaya St.
}

\begin{abstract}
Elements of the complex evaluation of inorganic waste condition to use it as a source of raw material for production of man-made soils with application of staged criterial selection are introduced. The proposed elements allow identification of waste which can be recycled to man-made soils within the waste-forming area of a region. Complex technology of sludge treatment prior to disposal is developed. The proposed system allows for reduction of expenditures on purchasing natural soils for recovery of disturbed territories, as well as waste placement costs.
\end{abstract}

\section{Introduction}

The growth of urban agglomerations leads to the extension of waste-forming area, which in this paper refers to a combination of waste sources and logistics of waste transportation. The most common large-capacity types of waste in waste-forming areas of the Central Russia are as follows: water industry sludge (WIS), sewage sludge (SS), oil sludge and oilcontaminated soils (OS \& OCS), overburden rocks (OR), demolition waste (DW), municipal solid waste (MSW) and drilling slurry (DS). Most of these types of waste contain mainly inorganic compounds. At the present time the vast majority of inorganic waste is disposed to storage pits.

Waste storage pits withdraw from use dozens of thousands of square kilometers of lands. Strengthening of the land and environmental legislation, as well as the need to develop disturbed lands, require creation of the methods for waste processing and disposal which ensure minimum impact on the natural environment components (NEC).

A promising direction of inorganic waste disposal is recycling into man-made soils (MMS) used for recovery and improvement of disturbed territories. This reduces the required amount of natural inorganic soils.

In order to involve inorganic waste into utilization to the maximum extent a complex system of waste processing and disposal with simultaneous land recovery is proposed. The system includes the following:

1. Stepwise evaluation of waste suitable for recycling taking into account resource, environmental and technological criteria of given waste-forming area;

\footnotetext{
* Corresponding author: vitaliy.pystin@yandex.ru
} 
2. Development and adaptation of the technology for waste treating in order to make it as similar as possible to the geoenvironment being recovered in terms of physical, chemical and geomechanics characteristics.

3. Use of multivariate data processing techniques for evaluation of suitability of waste deposits for utilization as a source of raw material for MMS production with division into groups by labor intensity at the stage of preparation to recycling. (FS)

4. Design of facilities for recycling of inorganic waste into MMS and feasibility study

Application of the complex system contributes to the efficient determination of waste disposal directions, including recovery of geoenvironment using MMS.

Utilization of MMS produced from neutralized inorganic waste covers the following directions of disturbed geoenvironment development:

- recultivation of landfills of municipal and industrial waste;

- remediation of lands degraded as a result of accidental spills of toxic substances;

- preparation of industrial sites for new construction;

- development of temporary transportation system in remote deposits of raw materials.

Borrow pits can often be located at a considerable distance from the areas being reclaimed, and their utilization is associated with additional impact on NECs. An alternative to natural borrow pits is man-made deposits of inorganic waste accumulated in storage pits, such as sludge dumps, drilling slurry pits, tailing dumps and mineralized MSW deposits. In this case systemic approach to evaluation of the condition of these objects can give grounds for possible use of waste for production of MMS, which will further be used for recovery of geoenvironment.

The first stage of the feasibility study is a criterial selection of the objects applying resource, environmental and technological criteria.

Resource criterion (1) shows practicability of the use of inorganic waste as a raw material for MMS production.

$$
R=\frac{V_{\text {was. }} \times k}{V_{\text {req. }}},
$$

where $V_{\text {req. }}$ - required volume of soil to perform the works on recovery of the land being developed;

$V_{\text {was. }}$ - actual total volume of inorganic waste within the boundaries of given waste-forming area;

$k(0 \ldots 1)$ - coefficient corresponding to the portion of inorganic component in waste, which constitutes a basis for shaping structure and individual soil-forming properties of MMS.

The optimal value of resource criterion is 1 , when the demand for natural soils is compensated by the MMS produced. If $\mathrm{R}<1$, then the amount of MMS is insufficient for recovery of the geoenvironment, and additional natural soils are required. If $\mathrm{R}>1$, there is risk of surplus production of the waste-based MMS, which will not be demanded further on.

Evaluation of waste-forming areas of the territories under study using resource criterion in most cases reveals excess of demand for soils over resources availability within the range of the geoenvironment being recovered. In its turn, the deficiency of natural soils can be covered by using low-toxic inorganic waste, and the second stage will provide environmental assessment of this waste.

At this stage geoenvironmental peculiarities of the territory under study are also evaluated, and the selection is made taking into account encumbrances restricting the works. This refers to the areas under special natural resource management, recreation areas, 
water conservation areas, close proximity of residential areas and a number of other restrictions.

Environmental criterion (2) gives grounds for the use of inorganic waste for MMS production in terms of its toxicity and the condition of the geoenvironment being recovered:

$$
E=\frac{I c_{\text {was. }}}{I c_{\text {geo. }}}
$$

where $\mathrm{Ic}_{\text {was. }}$ - waste contamination index;

$\mathrm{Ic}_{\text {geo. }}$ - geoenvironment contamination index.

Contamination index of the disturbed geoenvironment $\mathrm{Ic}_{\text {г.с. }}$, being recovered using MMS was assumed according to the existing regulatory documents [1], and it equals to 16 and 32, which, respectively, corresponds to acceptable and moderate contamination categories of grounds and soils. If $\mathrm{E}<1$, the waste is non-hazardous for the geoenvironment and can be used without restrictions. If $\mathrm{E}>1$, the waste requires neutralization prior to recycling. Complexity of processing and complex of methods for waste treating are associated with its evaluation by the technological criterion.

Table 1. Basic types, characteristics and processing technologies of large-capacity inorganic waste (Samara Region case study).

\begin{tabular}{|c|c|c|c|c|c|c|c|c|c|}
\hline \multirow[b]{2}{*}{$\begin{array}{l}\text { P. } \\
\text { No. }\end{array}$} & \multirow[b]{2}{*}{$\begin{array}{l}0 \\
0 \\
0 \\
3 \\
3 \\
0 \\
0 \\
0 \\
0 \\
0\end{array}$} & \multirow{2}{*}{ 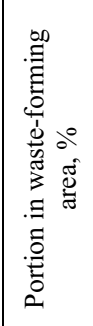 } & \multicolumn{5}{|c|}{ Basic waste characteristics* } & \multirow[b]{2}{*}{$\begin{array}{l}\text { Key component } \\
\text { determining the } \\
\text { method of treating }\end{array}$} & \multirow[b]{2}{*}{ Proprietary technologies } \\
\hline & & & 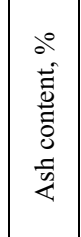 & 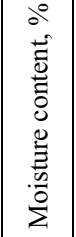 & 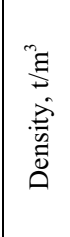 & 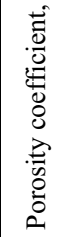 & 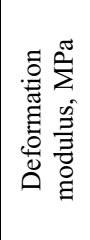 & & \\
\hline 1 & $\begin{array}{l}\text { Landfill } \\
\text { soils }\end{array}$ & $30-50$ & $40-60$ & $35-65$ & $\begin{array}{l}0.25- \\
1.25\end{array}$ & $\begin{array}{l}9.0- \\
12.0\end{array}$ & up to 1 & $\begin{array}{l}\text { Biodegradable } \\
\text { organics content; } \\
\text { Deformation modulus }\end{array}$ & $\begin{array}{l}\text { 1. Isolation [3]; } \\
\text { 2. Acceleration of waste deposit } \\
\text { settlement [4]; } \\
\text { 3. Surface cementation [5] }\end{array}$ \\
\hline 2 & WIS & $15-20$ & $70-98$ & $25-85$ & $\begin{array}{l}1.1- \\
1.3\end{array}$ & $\begin{array}{l}1.4- \\
3.0\end{array}$ & $1-3$ & $\begin{array}{l}\text { Moisture content; } \\
\text { Ash content }\end{array}$ & $\begin{array}{l}\text { 1. Geo-containerized dewatering; } \\
\text { 2. Mineralization; } \\
\text { 3. Strengthening [6]; }\end{array}$ \\
\hline 3 & $\begin{array}{l}\text { OS \& } \\
\text { OCS }\end{array}$ & $5-25$ & $60-95$ & $30-60$ & \begin{tabular}{|c|}
$0.7-$ \\
1.4 \\
\end{tabular} & $\begin{array}{l}4.0- \\
7.0 \\
\end{array}$ & $3-7$ & $\begin{array}{l}\text { Oil products } \\
\text { concentration }\end{array}$ & 1. Biodestruction [7] \\
\hline 4 & DS & up to 10 & $885-99$ & $40-80$ & $\begin{array}{l}1.1- \\
1.8\end{array}$ & $\begin{array}{l}1.2- \\
4.0\end{array}$ & $2-5$ & $\begin{array}{l}\text { Oil products } \\
\text { concentration; } \\
\text { Salts content } \\
\end{array}$ & $\begin{array}{l}\text { 1. Geo-containerized dewatering; } \\
\text { 2. Reagent treatment [8] }\end{array}$ \\
\hline 5 & SS & up to 5 & $20-60$ & $65-95$ & $\begin{array}{l}0.8- \\
1.2\end{array}$ & - & $\begin{array}{l}\text { up to } \\
0.5\end{array}$ & $\begin{array}{l}\text { Moisture content; } \\
\text { Ash content; } \\
\text { Pathogenic microbial } \\
\text { flora content }\end{array}$ & $\begin{array}{l}\text { 1. Mechanical and geo- } \\
\text { containerized dewatering; } \\
\text { 2. Biothermal treatment with } \\
\text { thermophilic phase extraction [9] }\end{array}$ \\
\hline
\end{tabular}

A key principle for selection of treatment technology is to achieve maximum similarity between composition, properties and structure of inorganic waste and the geoenvironment being recovered. For this purpose the use of proprietary technologies of waste preparation is proposed with taking into account separate and combined application of field and mechanized methods of treatment. The complex of these methods shall provide minimum impact on the natural environment components. Selection of technologies and technological sequence depends on natural and mane-made characteristics of waste, its origin, as well as similarity between the content of key components in the waste and the geoenvironment [2] (Table 1). 
According to research data of Samara State Technical University in 2000-2015.

Analysis of the table shows that the main obstructions for the direct use of waste as MMS are high moisture content and presence of organics. These characteristics along with fine texture and low density of inorganic component of waste prevent direct use of the waste as MMS without preliminary treatment. When using MMS, their properties shall comply with the requirements for natural soils. Level and complexity of the required treatment of waste in order to bring its properties into line with the parameters of the geoenvironment being recovered are evaluated using technological criterion (3).

$$
I_{(E, \tau)}=\left\{I_{W}=\frac{W_{\text {was }}}{W_{M M S}} ; I_{\rho}=\frac{\rho_{\text {was. }}}{\rho_{M M S}} ; I_{M}=\frac{M_{\text {was. }}}{M_{M M S}} ; \ldots,\right.
$$

where $\mathrm{I}_{(\mathrm{E}, \tau)}$ - integral criterion of mechanical properties of MMS;

$\mathrm{I}_{\mathrm{w}, \rho, \mathrm{M}}, \ldots-$ criteria of dewatering, density and fineness modulus, respectively;

$w, \rho, M-$ moisture content, density and fineness modulus of inorganic component of waste and man-made soil, respectively.

Combined evaluation of waste condition using technological criterion allows determining methods, their sequence and level of controllable treating for achieving the required characteristics of the MMS produced. As a result of this stage of selection types of waste are divided into groups differing by the methods of treating. Multivariate evaluation in this case allows determining the required complex of methods for treating waste in order to transform it into MMS with desired characteristics (Fig. 1).

The Figure shows a flowchart for production of MMS with specified level of responsibility from the waste with initial characteristics (governing parameters) which involves application of one or another method of treatment (controllable treating).

The flowchart also represents the suggested directions of use of MMS obtained by sequential application of controllable waste treating. In this case the treating (technologies) combination is determined by both initial characteristics of the waste being treated and the intended use of MMS. Generally, large-capacity inorganic waste, in most cases, is not acutely toxic (WIS) and can be used as replacement for natural soils after geo-containerized dewatering. Some types of waste contain organics and can be neutralized using the methods of mineralization (SS, OCS), some of them can be processed using binding and adsorbing additives (DS). MSW and dewatered WIS can be involved into construction operations through strengthening of waste deposits.

For designing of waste recycling facilities, as well as in order to create and adept treatment technologies, an integrated survey of the condition of waste deposits and associated disturbed lands is required using the methods of engineering surveying. Evaluation of the condition refers to the need of obtaining reliable information about structure and properties of the waste deposits. Generally, these data are collected for qualitative and quantitative evaluation of adverse effects of waste for the geoenvironment and do not allow considering the waste as a source of raw material for MMS production.

Condition of the disturbed territories, in general, and waste deposits, in particular, are evaluated through a large number of parameters which determine selection of treatment methods and directions of further development of lands. For easier evaluation of the condition of multiple waste storage pits and associated disturbed territories, as well as selection of methods of recovery, a classification is proposed to divide them into groups by the combination of characteristics using multivariate data analysis [10].

Multivariate data analysis was successfully used by the specialists from Samara State Technical University for evaluation of MSW, OCS, WIS and SS waste deposits $[11,12,13]$. 


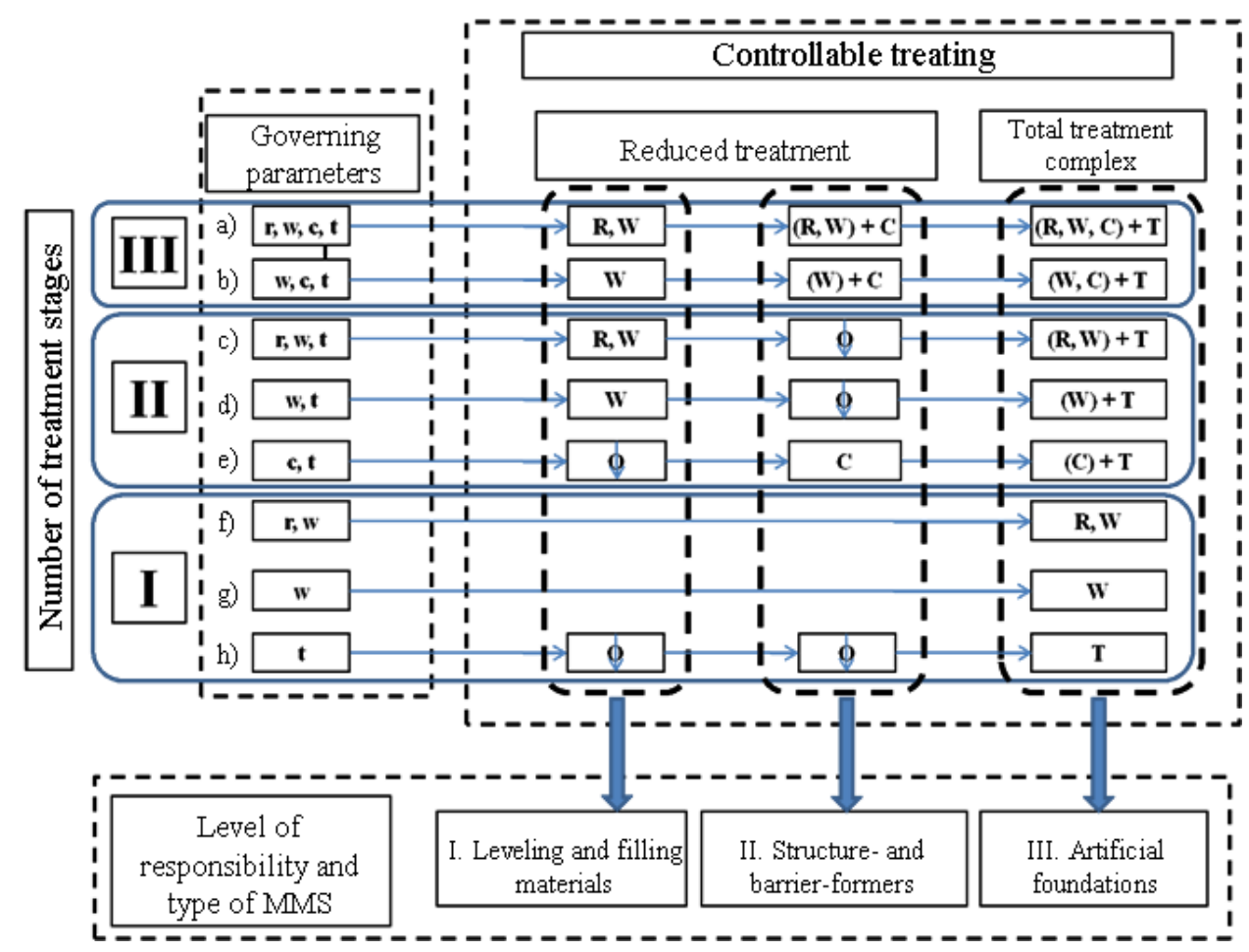

Explanation:

$\mathrm{r}, \mathrm{w}, \mathrm{c}, \mathrm{t}$ (high specific filtration resistance, high moisture content, presence of degradable organics and low strength, respectively) - parameters, which determine the need for the various methods of controllable waste treating.

$\mathrm{R}, \mathrm{W}, \mathrm{C}, \mathrm{T}$ (conditioning, dewatering, mineralization and strengthening, respectively) methods of controllable initial waste treating.

$\mathrm{O}$ - possibility of using waste as MMS without additional treatment.

Fig. 1 Flowchart for classifying initial sludge by types of man-made soils after selected treatment stages.

This approach allows selecting qualified directions of disposal for the accumulated waste and classifying waste deposits by possible prospects of using them for MMS production.

Apart from that, special aspects of this evaluation method allow identifying waste deposits with excess moisture, organics and toxic components contents, which require treatment and neutralization.

Known methods of treating such waste involving mechanized techniques usually require construction of capital facilities, purchasing expensive equipment and considerable energy costs. In many cases negative economic effect from utilization of such technologies is accompanied by minimum environmental effect, and the result is generation of waste which requires burying. In addition, the limiting factor for the implementation of these methods is that the waste deposits are often locate at a large distance from the developed engineering infrastructure. Therefore, sludges preparation shall be carried out using technically available and environmentally efficient methods. These methods include geocontainerized dewatering, mineralization, reagent neutralization and strengthening $[6,7,8]$. 
Sequential selection of waste by resource, environmental and technological criteria within the implementation of the proposed system makes it possible to develop efficient and technically available technologies of MMS production using geo-containerized dewatering, stacked layers mineralization and strengthening, as well as realize this technological sequence in the form of waste recycling facilities (Fig. 2).

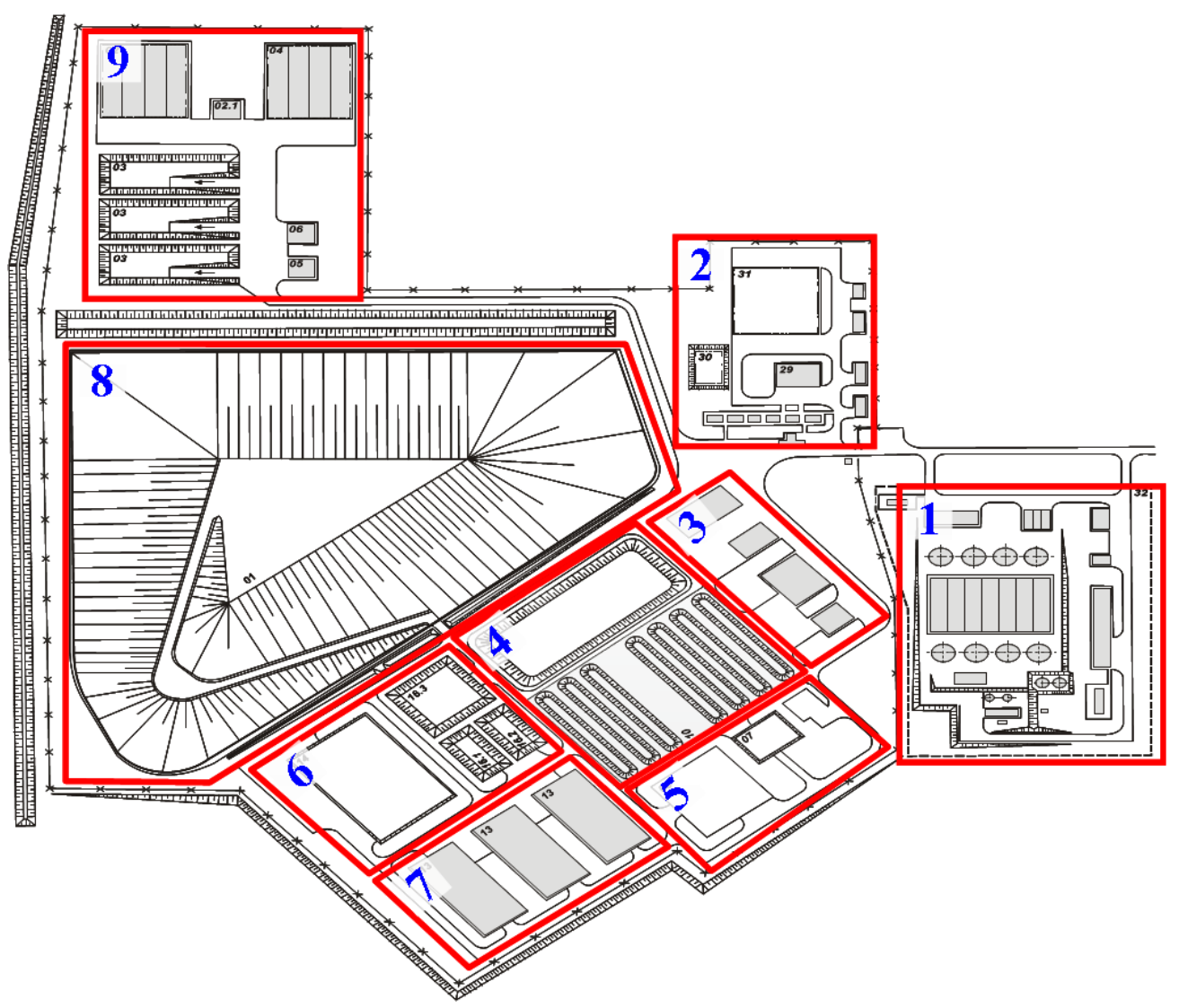

Explanation:

1 - Area of delivery, incoming inspection and preparation of waste; 2 - Area of auxiliary facilities; 3 - Area of temporary accumulation of reagents and materials; 4 - Area of OS \& OCS treatment; 5 - Area of MMS strengthening; 6 - Area of DS reagent neutralization; 7 Area of WIS geo-containerized neutralization; 8 - Area for placement of neutralized fractions of waste; 9 - Area of temporary accumulation of toxic waste components.

Fig. 2 Facilities for inorganic waste recycling with MMS production

\section{Conclusion}

The provisions represented in this paper were used in designing the facilities for sludge waste recycling and recultivation of disturbed geoenvironmental compartments in Novokuybyshevsk urban agglomerations in Samara Region. Treatment of inorganic waste and its recycling to MMS used for recovery of the geoenvironment will allow reducing required amount of natural soils down to 20,000 ths. $\mathrm{m}^{3} /$ year. 


\section{References}

1. SanPiN 2.1.7.1287-03. Sanitary and Epidemiological Requirements on Quality of Soil (2003).

2. D.E. Bykov, Complex Multi-Level System of Examination and Recycling of Industrial Waste, 102 (2003)

3. Patent 2318619 RF, Method for Coating Formation on Waste Storage Pits No.2006124064/03 (2013).

4. Patent No. 2487767 RF, B09B1/00. Method for Disposal of Municipal Solid Waste and Device for Its Implementation, No. 2011117255/13 (2013)

5. K.L. Chertes, A.A. Savelyev, O.V. Tupitsyna, E.G. Martynenko, Proceedings of the 5th International Ecological Congress (the 7th International Scientific and Technical Conference), 283-290 (2015)

6. V.N. Pystin, Bulletin of Moscow State University of Civil Engineering 2, 110-129 (2015)

7. D.V. Zelentsov, Ecology and Industry of Russia, 33-34 (2011)

8. V.N. Pystin, Ecology and Industry of Russia 6, 13-17 (2014)

9. Patent No. 1816742 RF Method of Biothermal Treatment of Sewage Sludge (1991)

10. K.H. Esbensen, Multivariate Data Analysis In Practice 4-th Ed. (2000)

11. V.V. Ermakov, Classification of Oil Sludge Dumps and Prediction of Waste Biodestruction Process during their Liquidation (2010)

12. V.N. Pystin, Bulletin of Moscow State University of Civil Engineering 6, 88-101 (2015)

13. O.V. Tupitsyna, Development of Natural and Man-made Systems of Urban Agglomerations (2014) 